\title{
Testing the Model of Information System of Innovative Management in Education
}

Vorontsova, L.V.a

Safiullin L.N. ${ }^{b}$

Kramin, M.V.c

Grigoryev R.A.d

\author{
acd Institute of Economics, Management and Law, Kazan, Russian Federation, 420111 \\ ${ }^{b}$ Kazan Federal University, Institute of Management, Economics and Finance, Kazan, 420008, Russia
}

\section{Doi:10.5901/mjss.2015.v6n1s3p91}

\section{Abstract}

The work presents the results of testing the model of information system of innovative management in education on the example of Institute of Economics, Management and Law (Kazan) based on transactional approach, taking into account the classical theory of transaction costs. Classifications of transaction costs, most applicable in corporate hierarchies, are used. Special emphasis is made on the descriptions of economic effects of the information system implementation in an educational establishment.

Keywords: transaction costs, information system, educational establishment

Transaction costs run through the whole management system of a modern company. Transaction costs management possesses a huge potential of increasing the company's potential and competitiveness, especially in Russia. This potential is especially important in hi-tech and science intensive sectors, including educational sphere (Ashford \& Biswas, 2010), as transaction costs often constitute more than a half of all their expenses.

An important role in transaction costs management is played by corporate information systems of educational establishments (Sullivan, 2009; Violino, 2008). The number of educational establishments which implement them is growing every year. However, using information systems ${ }^{1}$ to reduce transaction costs of an educational establishment is not always conceptual and systemic (Jones, 2009).

The work presents the results of testing the model of information system of innovative management in education on the example of Institute of Economics, Management and Law (Kazan) based on transactional approach (Воронцова, Крамин, \& Крамин, 2011; Крамин, 2007a), taking into account the classical theory of transaction costs. Classifications of transaction costs, most applicable in corporate hierarchies, are used. Special emphasis is made on the descriptions of economic effects of the information system implementation ${ }^{2}$ in an educational establishment, based on the transaction costs approach (Robins, 1987).

One of the most general characteristics of transaction costs was given by Kenneth Arrow, who defined them as costs " to keep the economic system going" (Arrow, 1969). This definition expresses the essence of transaction costs and emphasizes their integral character. Thus, K. Arrow defines transaction costs as costs of economic system implementation.

By D. North, "transaction costs are costs conditioned by the character of productive relations" (North, 1973), which consist of "costs of evaluating the object's useful properties and costs of ensuring rights and forcing for their observance" (North, 1990).

It is well known that under the limited rationality of agents and choice uncertainty the institutions are intended for solving the problems of motivation and coordination. Taking this fact into account, Paul Milgrom and John Roberts (Milgrom, 1992) proposed classification of transaction costs according to the key spheres of problems generated by them

${ }^{1}$ For the stages of introducing information systems see also "stages of ERP systems development" (Esteves \& Pastor, 1999; Sabau, Munten, Bologa, Bologa, \& Surcel, 2009).

2 Investments connected with implementation of information systems in educational establishments are considered to be most significant. Costs classification can be found in the work by E. Babey (Babey, 2006). 
(Кузьминов, Бендукидзе, \& Юдкевич, 2013). By their classification, transaction costs can be divided into coordination costs and motivation costs.

Coordination costs are costs aimed at providing the temporal and spatial coordination of the transaction participants. Such costs can occur both within the company and in market transactions. Within the company, which is a hierarchical structure, the coordination costs are costs of transmitting information by the different levels of the company, costs of elaborating the plan of activity, presenting the plan to the personnel and its implementation. In the market the coordination costs are connected with defining the price for goods and the characteristics of potential partners, as well as mutual referring to this information. Besides, coordination costs include the time spent.

Motivation costs are costs motivating the parties of transaction to fulfil their duties; these are costs for controlling, information collection, monitoring of the mutual liabilities' observance by the partners, etc. These costs, like coordination costs, can occur both within the company and in the market, which is conditioned by two factors: opportunism of the participants of transaction and imperfection and incompleteness of information. Thus, motivation costs can be expressed by costs for infrastructure formation, which will stimulate the agents to enter the transaction.

Milgrom-Roberts classification is especially convenient for the analysis of transaction costs occurring in intracompany hierarchies. It allows to define how to minimize costs for coordination of the personnel actions, how to effectively organize the information flow, and how to assess the effect of information distortion during its flow along the company's hierarchical levels.

Milgrom-Roberts classification allows to distinguish the potential sources of transaction costs. However, it is quite hard to assess the costs of a particular transaction, by using this classification. For that purpose another classification is often used, namely North-Eggertsson classification. It is based on constructing the external elements of a particular transaction, which leads to occurring the corresponding costs, and allows to distinguish them while its stages are realized. According to North-Eggertsson classification, six types of transaction costs are singled out (Eggertsson, 1990):

- information search costs;

- negotiation costs;

- contracting costs;

- monitoring costs;

- costs of forcing to execute contracts;

- costs of protection against third parties.

By $\mathrm{O}$. Williamson, transaction costs include "... comparative costs of planning, adapting and monitoring task completion under alternative governance structure" (Williamson, 1985, p. 2). This definition directly points out the necessity of choosing the available alternative managerial structure.

The proposed functional definitions and classifications are used in the present work to test the model of information system of innovative management in education based on transactional approach. To fulfil this task, the characteristic is given of the model of innovative management information system, which is being developed in Institute of Economics, Management and Law (Kazan), from the point of view of the above described classifications of transaction costs.

To reduce coordination costs (information transfer and planning of activity), the corporate information system gives a number of opportunities provided by its features:

1. Access to the system from the Internet. The employees can work from home or from abroad without installing any additional software and without physical connection to a particular working place. For that any computer with the Internet access is sufficient.

2. Prompt input of information into the system at the point of its appearance. For example, the published data of a student are inputted not in the Dean's office, but in the Admission Commission, where they are submitted.

3. Strict regulation of forming and using the information flows. Each employee has a working place in the system, which is determined by the personal name and access rights, and executes the same tasks as during manual documentation circulation. As a result, the high efficiency of introducing and implementing the system is achieved.

4. Information protection and minimization of information loss risks. Data transfer is carried out via protected canals with ciphering. In case of equipment errors, the system functioning and all data can be restored in a few minutes.

5. Accounting, planning and calculation of costs by faculties, departments, specialties, and forms of education by integrating Idis. Education into accounting systems.

6. Prompt access of the Institute administration to corporate information, with the demanded level of detailing from any point with the access to the Internet.

7. The system provides information transfer for all participants of the educational process. Besides, the system is 
used for automatization of planning their activity. The main users of the system, from the point of view of information transfer and planning, are (functional specialization of the system for each group of users is given in brackets):

- Matriculants (registration, filling in the form, competition results).

- Admission commission (data receiving, competition implementation, signing contracts, statistics).

- Students (on-line schedule, progress, search of professors, correspondence with the professors, contacts with employers, personal page of a student, etc.).

- Academic-methodological department ${ }^{3}$ (planning the educational process, academic-methodological provision, studying programs).

- Department (planning and distributing the teaching load, individual plans professors, etc.).

- Professors (on-line schedule, planned and actual load, progress reports, distributing of teaching materials, personal page of a professor).

- Employers (selecting students and graduates, monitoring of potential employees).

- Administration (prompt vision of the complex pattern of the educational establishment both with detailing of each information element and in consolidation on-line).

8. Automatization of operations at each working place.

9. Accumulation and aggregation of the information.

10. Forming the integral reporting system. Integrating the system with other software used by the educational establishment: electronic documentation circulation, accounting, and other software.

11. Organizing the centralized using of information resources and competitive advantages of each dependent educational establishment (electronic catalogs and libraries, personnel potential, etc.).

12. Planning activity on the basis of key indicators.

13. Elaborating the development strategies.

At the stage of planning and distribution of the teaching load, the institute can actually model the whole educational process and promptly change the decisions if needed.

The presented information system is also aimed at reducing motivation costs (controlling costs, information collection costs, costs of monitoring of liabilities execution during transactions between participants of educational process):

1. Providing quality control of educational process.

2. Regulation of departments' activity.

3. Opportunity to trace changes (structure of admission, contingent, demand for graduates, staff composition, costs, etc.) and promptly react to them.

4. The main users of the system from the point of view of motivation costs management are:

- Dean's office (private information registration, personal data, forming the students' contingent, progress, etc.).

- Academic department (organization and control of the educational process, automatization of schedule formation, teaching load forming, etc.).

- Human resources department (automatization of employees' registration, analysis of employees' composition, staff list).

- Administration (monitoring and control of the whole educational process)

5. Providing the educational establishment (and its administration) with new methods of management: methods of scenario analysis, methods of project management, methods of economical-mathematical modelling.

6. Prompt reacting to changes of key efficiency indicators.

7. Creating additional motivation factors for employees; forming of their involvement into the general process, realizing their mission, strategic goals of the organization, belonging to the common cause.

8. Excluding the duplicating functions of the departments of the organization.

9. Ensuring the principle of synchronizing the employees' activity.

10. Systemic associativity of all indicators.

11. Obligatory coordination of planned indicators and actual data.

12. Automatization of classroom and professors stock management. The resource base built into the program is interactive schedule, formed automatically.

${ }^{3}$ See also on the features of curriculum integration (Hepner \& Dickson, 2013; Joseph \& George, 2002; Watson \& Schneider, 1999) 
13. Initiating activities and setting tasks for the chosen strategy implementation.

14. Analyzing managerial information and tracing the decision making.

15. Carrying out the complex of works for managing the educational establishment.

16. Forming the system of labor market demands monitoring and their satisfying by educational establishments included into the community of users.

Similarly, one can classify the functional possibilities of the described information system by the North-Eggertsson grouping of transaction costs.

Below we present the examples of transaction costs reduction in Institute of Economics, Management and Law (Kazan) as a result of introducing the corporate information system according to the North-Eggertsson classification of transaction costs.

As a result of reducing the costs of information search and contracting in the functioning of the Institute's Academic department, the number of employees in that department has not increased during several recent years, while the number of students increased several times, as well as the number of specialties. Besides, transition to the two-level system of education 2011 significantly and sharply increased the load on the Academic department. However, due to information system, the employees successfully managed the new tasks.

Negotiation costs and contract execution costs were also reduced due to information system introduction. This fact can be illustrated by the process of departments' enlarging by uniting the main institute's departments with departments in the branches.

As a result the administrative-managerial apparatus was reduced, as well as the documentation circulation, and the volume of information to be traced and controlled. At the same time the quality and promptness of departments' management increased due to unification, transparency growing, etc.

Monitoring costs have also significantly reduced. Before introducing the information system, it was rather hard to obtain some indicators, such as unit costs by specialties, forms of education, particular streams and groups. Promptness of data obtaining was very low. The information system allowed to significantly broaden the range of the calculated indicators. Besides, the automatization of their calculation made it possible for the Institute's administration to trace the situation on-line. In particular, as a result of prompt monitoring of the structure of unit costs, the Institute's financialeconomic department continuously reveals the unprofitable directions of activity and makes appropriate managerial decisions. The mentioned new possibilities of the educational process management became available without additional increase of the personnel of financial-economic department.

One can calculate the economic effect of each case of implementing and testing the model of information system of innovative management in education (Ansari, 1997) basing on scenario analysis and project management. For that two scenarios of the Institute's functioning are viewed - without the information system and after its introducing. The differences in cash flows between the two scenarios can be viewed as the cash flow of the virtual project of introducing the information system in the Institute. Such calculations will be presented in further publications.

Thus, introducing the information system in an educational establishment allows to systematize and automatize the documentation circulation, to ensure transparency, homogeneity and validity of managerial decisions; ensures availability of any reports (by employees, students, graduates, etc.) at any time and place where the Internet is available; organization of control over budget and off-budget expenses; centralization of information resources an labor market monitoring.

All that ensures the stable, dynamic and efficient management of the educational establishment based on the efficient using of the available resources and systemic management of its transaction costs.

\section{References}

Ansari, M. M. (1997). Cost Effectiveness of Higher Education: A Critical Assessment: Concept Publishing Company.

Arrow, K. J. (1969). The organization of economic activity: issues pertinent to the choice of market versus nonmarket allocation. The analysis and evaluation of public expenditure: the PPB system, 1, 59-73.

Ashford, R., \& Biswas, S. (2010). Aid effectiveness, transaction costs and conditionality in the education sector. International Journal of Educational Development, 30(5), 481-487.

Babey, E. R. (2006). Costs of enterprise resource planning system implementation-And then some. New Directions for Higher Education, 2006(136), 21-33.

Eggertsson, T. (1990). Economic behavior and institutions: Principles of Neoinstitutional Economics: Cambridge University Press.

Esteves, J., \& Pastor, J. (1999). An ERP lifecycle-based research agenda. Paper presented at the 1st International Workshop in Enterprise Management \& Resource Planning.

Hepner, M., \& Dickson, W. (2013). The Value of ERP Curriculum Integration: Perspectives from the Research. Journal of Information 
Systems Education, 24(4), 309.

Jones, M. (2009). The Strategic Academic Enterprise: Why ERPs Will No Longer Be Adequate. College and University, 84(4), 55.

Joseph, G., \& George, A. (2002). ERP, learning communities, and curriculum integration. Journal of Information Systems Education, 13(1), 51-58.

Milgrom. (1992). Economics, organization and management: Prentice-Hall International.

North, D. C. (1973). The rise of the western world: A new economic history: Cambridge University Press.

Sullivan, L. S. (2009). Post-implementation success factors for enterprise resource planning (ERP) student administration systems in higher education institutions: University of Central Florida.

Violino, B. (2008). ERP= Efficiency. Community College Journal, 79(1), 28-30.

Watson, E. E., \& Schneider, H. (1999). Using ERP systems in education. Communications of the AIS, 1(2es), 3.

Bagautdinova, N.G., Novenkova, A.Z., Sarkin, A.V. Quality management system formulation and implementation as a factor of enhancement of the university role in the local development // World Applied Sciences Journal, 27(13), 2013, 38-42.

Williamson, O. E. (1985). The economic intstitutions of capitalism: Simon and Schuster.

Novenkova A.Z., Maklakova N.V. Internal Canibalization of University Brands in the Process of Enlargement and Merger// Mediterranean Journal of Social Sciences.- Vol.5, No12, (2014)-pp.163 - 165.

Bagautdinova, N.G., Tsvetkova, G.S., Novenkova, A.Z. The interaction of formal and informal market institutes // World Applied Sciences Journal, 27(13), 2013, 58-61. 